\title{
EFFECT OF LYOPHILIZED JUICE OF PUNICA GRANATUM L. IN ANTINOCICEPTIVE AND INFLAMMATORY PAIN
}

\author{
JOSE ANTONIO GUERRERO-SOLANO ${ }^{1}$, MIRANDELI BAUTISTA ${ }^{1}$, NELLY DEL SOCORRO CRUZ-CANSINO무, \\ ALEJANDRO CHEHUE-ROMERO ${ }^{1}$, OSMAR ANTONIO JARAMILLO-MORALES ${ }^{2 *}$
}

${ }^{1}$ Health Sciences Institute, Autonomous University of Hidalgo State, Circuito Ex Hacienda La Concepción, km 1.5. C.P. 42160, San Agustín Tlaxiaca, Hidalgo, Mexico. ${ }^{2}$ Department of Nursing and Obstetrics, Division of Life Sciences, University of Guanajuato, Ex Hacienda el Copal, km 9 Irapuato-Silao Highway Ap 311, Irapuato, Guanajuato 36500, Mexico.

Email: oajmorales@gmail.com/oa.jaramillo@ugto.mx

Received: 31 October 2019, Revised and Accepted: 25 December 2019

ABSTRACT

Objective: The aim of this study was to explore the analgesic activity of lyophilized juice of Punica granatum L., obtained from Hidalgo, Mexico, in the formalin test.

Methods: We extracted the juice manually, filtered it and then dried down in a lyophilizer machine. We evaluated the antinociceptive effect of lyophilized juice from pomegranate in the formalin test (2\%) in male Wistar rats (180-200 g body weight). Thirty minutes before the test, a dose of $316 \mathrm{mg} / \mathrm{kg}$ (lyophilized juice) and acetylsalicylic acid as reference drug $(100 \mathrm{mg} / \mathrm{kg})$ both were administered intragastrically (i.g.).

Results: The oral administration of lyophilized juice of pomegranate showed a significant decrease in the number of flinches in the temporal course and a significant antinociceptive effect in nociceptive and inflammatory pain compared with the vehicle. In the same way, this effect appeared with the drug of reference (acetylsalicylic acid $100 \mathrm{mg} / \mathrm{kg}$ i.g). Furthermore, it was shown that juice had a $34 \%$ of antinociception on overall effect versus vehicle.

Conclusion: The results suggest that lyophilized juice of pomegranate has antinociceptive effect in nociceptive and inflammatory pain. Therefore, this study supports the possible use of this lyophilized juice of pomegranate in the treatment of pain.

Keywords: Antinociceptive, Lyophilized juice, Punica granatum L, Pomegranate, Formalin test.

(C) 2021 The Authors. Published by Innovare Academic Sciences Pvt Ltd. This is an open access article under the CC BY license (http://creativecommons. org/ licenses/by/4.0/) DOI: http://dx.doi.org/10.22159/ijap.2021.v13s1.Y0055. Journal homepage: https://innovareacademics.in/journals/index.php/ijap

\section{INTRODUCTION}

Pain is a symptom and often is the main cause of seeking professional help to get relief. The most common disorders are inflammatory pain and nociceptive pain [1]. Nowadays, the pain has become an invisible epidemic that affects $20 \%$ of the adult population, with clinical and socioeconomic consequences, affecting the quality of life [2].

This scenario prompts the search for new compounds with therapeutic efficacy to solve these problems [3]. In this regard, natural products have played a significant role in developing and discovering new active ingredients with analgesic properties [4].

Pomegranate is a tropical and subtropical fruit of a tree called pomegranate (Punica granatum L.), and its use is associated with multiple beneficial effects on health, due to its bioactive compounds (ellagitannins and anthocyanins being the most abundant) [5]. One of these effects is its use against pain; in traditional medicine, pomegranate has been used for sore throat, toothaches, canker sores, and stomach [6]. Moreover, in preclinical studies, it has been shown that the use of different extracts from this fruit exhibits antinociceptive effects in nociceptive and inflammatory pain [7-10]. Nevertheless, pomegranate effects on nociceptive behavior have been poorly explored, and there are no studies evaluating this antinociceptive effect in pomegranate varieties from Hidalgo, Mexico. In this regard, the objective of this study was to evaluate the antinociceptive activity of lyophilized juice of $P$. granatum L., obtained from Hidalgo, Mexico, in the formalin test in rats.

\section{METHODS}

Plant material and extraction

P. granatum L. was collected at Tasquillo Municipality in Hidalgo State, Mexico, during August-October 2019. The juice was extracted manually by squeezing the arils and then, filtered and lyophilized using a lyophilizer machine (Labconco Model Freezone 4.5, Kansas City, MO, USA) at a temperature of $-40^{\circ} \mathrm{C}$. Specimen was identified at the Botany Department of the Bachelor of Biology from the Institute of Basic Sciences and Engineering at Autonomous University of the State of Hidalgo. Voucher specimens were deposited at the Pharmacognosy Department.

\section{Animals and housing conditions}

Male Wistar rats (180-200 g of body weight) were used to perform this study. The rats were housed in a room under standardized conditions, on a $12 \mathrm{~h}$ light/dark cycle with food and water available ad libitum before treatment. All experimental procedures were approved by the Internal Institutional Animal Care and Use Committee and followed the Guidelines on Ethical Standards for Investigations of Experimental Pain in Animals [11] and the Official Mexican Norm (NOM-062Z00-1999). In addition, the experimental procedures were approved by the Ethical Committee of the Autonomous University of the State of Hidalgo (CICUAL010-2019). All tests were performed during the light phase. The number of rats was kept at a minimum, and all animals were euthanized in the end.

\section{Compound}

The concentration of formalin (2\%) was prepared by diluting a saturated aqueous solution of formaldehyde (37\%) (Merck, Mexico) with a sterile physiological saline solution.

Acetylsalicylic acid was obtained commercially from Sigma-Aldrich (St. Louis, MO, USA). Acetylsalicylic acid was suspended in $0.5 \%$ carboxymethylcellulose and was administered orally in an application volume of $4 \mathrm{ml} / \mathrm{kg}$ body weight. 
Measurement of antinociceptive activity

The formalin-induced flinches test was used as previously described [12]. All treatments were orally administered $30 \mathrm{~min}$ before the $2 \%$ formalin injection $(50 \mu \mathrm{l})$ subcutaneously in the dorsal right hind paw. The number of flinches (nociceptive behavior) of the injected paw was quantified over $1 \mathrm{~min}$, every $5 \mathrm{~min}$, up to $1 \mathrm{~h}$ after injection. The mean number of flinches constructed time-courses of the antinociceptive response of the different treatments. The area under the curve (AUC) of the number of flinches against each treatment time was calculated [13]. Antinociception is presented as the percent antinociception, calculated from AUC of phase 1, phase 2, and the overall effect of the formalin test; according to the following equation:

$$
\% \text { Antinociception }=\frac{\text { AUc vehicle-AUC post-compound }}{\text { AUC vehicle }} \times 100
$$

Formalin-induced flinching behavior was biphasic [14]. The initial acute phase (0-10 $\mathrm{min}$ ) was followed by a relatively short quiescent period, which was then followed by a prolonged tonic response (15-60 min).

\section{Statistical analysis}

All data were expressed as the means \pm SEM and were checked for normality using the Shapiro-Wilk test. The antinociceptive response was analyzed using an analysis of variance test for between-group comparisons, followed by the post hoc Tukey test. In all of the statistical analyses, ${ }^{*} \mathrm{p}<0.05$ was considered statistically significant. The studies were performed using GraphPad Prism 6.0 software (GraphPad Software, Inc., La Jolla, CA, USA).

\section{RESULTS}

Fig. 1 shows the time course of the number of flinches in response to the administration i.g. of the vehicle, acetylsalicylic acid, and lyophilized juice of P. granatum L. in the formalin test (2\%). The administration of the vehicle showed a significant increase in the number of flinches; this behavior reflects a nociceptive behavior. However, the administration of both treatments i.g. (acetylsalicylic acid and lyophilized juice) showed a significant decrease in the number of flinches, indicating an antinociceptive effect.

It is well known that formalin administration produces two phases of nociceptive behavior: The first one is directly linked to the stimulation of primary sensory neurons and is followed by a second phase, which is associated with inflammation and involves central sensitization [14]. Fig. 2 shows the oral administration of lyophilized juice of $P$. granatum L., and acetylsalicylic acid exhibited a statistically significant antinociceptive effect compared to their control group ( $\left.{ }^{*} \mathrm{p}>0.05\right)$ in both phases. However, acetylsalicylic acid administration showed a

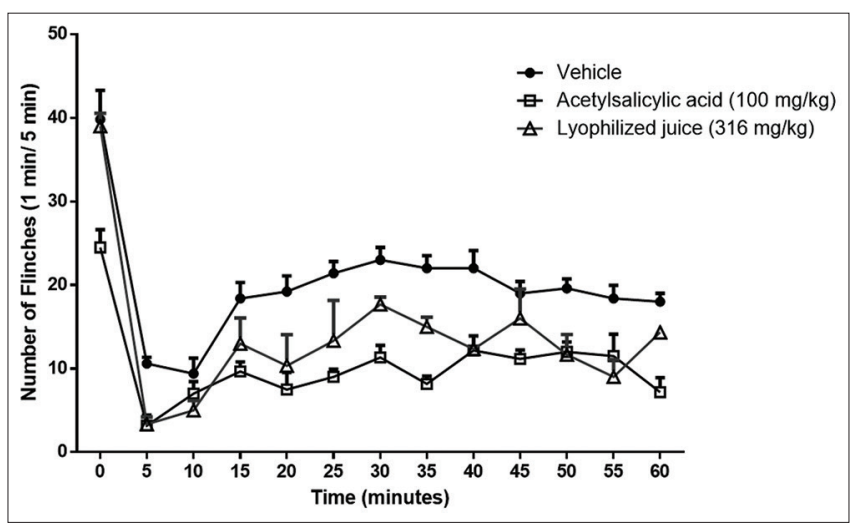

Fig. 1: Temporal course of the effect on the number of flinches generated by acetylsalicylic acid and lyophilized juice of Punica granatum $L_{\text {., }}$ in the formalin test. The animals were administered with vehicle $(0.5 \%$ carboxymethylcellulose) or single doses of acetylsalicylic acid (100 mg/kg i.g.) and lyophilized juice of $P$. granatum L. (316 mg / kg i.g.) Each point represents the mean \pm SE more significant antinociceptive effect in phase 2 (inflammatory pain) than lyophilized pomegranate juice.

When analyzing both overall phases effect, it can be seen that orally administration of acetylsalicylic acid (100 mg/kg, i.g.) and lyophilized juice (316 mg/kg, i.g.) showed a statistically significant effect on the decrease in nociceptive behavior. This statistically significant effect was calculated as the maximum, obtaining the highest percentage of antinociception for acetylsalicylic acid $41 \%$ and lyophilized juice of P. granatum L., 34\% (Fig. 3)

\section{DISCUSSION}

The formalin test is a robust model to study acute and tonic inflammatory pain [14], and it has been demonstrated to be sensitive to various analgesic drugs [15]. In the present study, formalin (2\%) injection produced the expected nociceptive response in rat receiving vehicle $(0.5 \%$ carboxymethylcellulose).

Besides, nonsteroidal anti-inflammatory drugs as diclofenac acetylsalicylic acid, indomethacin, and naproxen have been previously

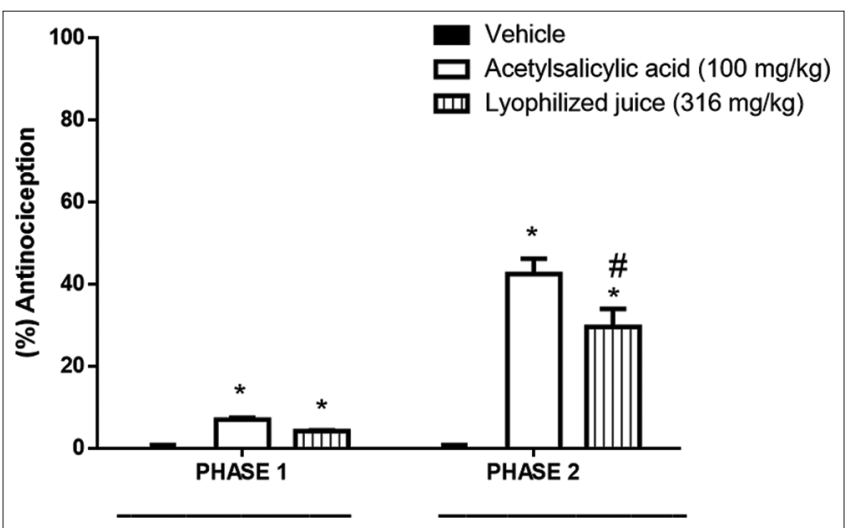

Fig. 2: Antinociceptive effect observed after oral administration of acetylsalicylic acid (100 mg/kg, i.g.) and lyophilized juice (316 $\mathrm{mg} / \mathrm{kg}$, i.g.) during phases 1 and 2 of the $2 \%$ formalin test. Data were expressed as the percent of antinociception. Each point represents the mean $\pm S E, n=6 .{ }^{*} p<0.05$, significantly different from the vehicle group; ${ }^{\#} \mathbf{p}<0.05$ acetylsalicylic acid versus lyophilized juice

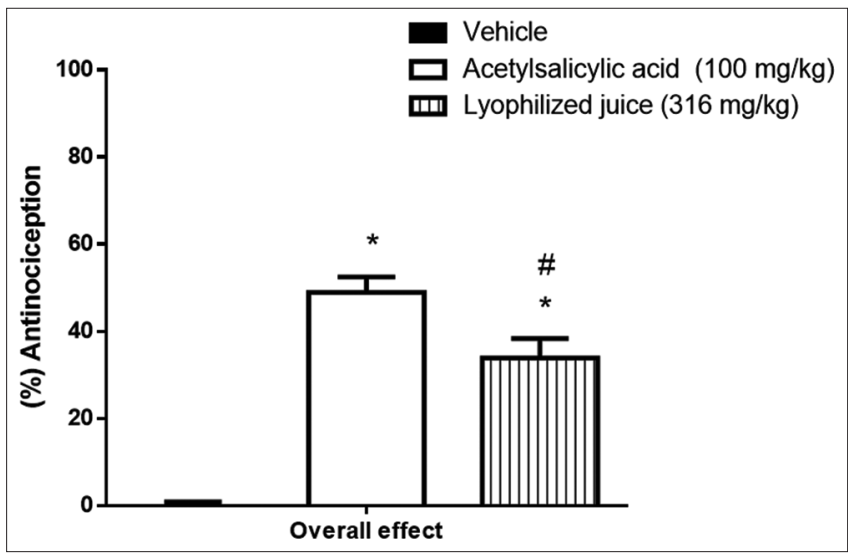

Fig. 3: Antinociceptive effect observed after oral administration of acetylsalicylic acid (100 mg/kg, i.g.) and lyophilized juice (316 $\mathrm{mg} / \mathrm{kg}$, i.g.) during the overall effect of the $2 \%$ formalin test.

Data are expressed as the percent of antinociception. Each point represents the mean $\pm S E, n=6 .{ }^{*} p<0.05$. Significantly different from the vehicle group; ${ }^{\# p}<0.05$ acetylsalicylic acid versus lyophilized juice 
shown to exhibit clear antinociceptive effects in the formalin test in rats [15]. These studies demonstrated that acetylsalicylic acid reduces nociceptive behavior in both phases [15] for the block prostaglandin synthesis [16]. These results are in agreement with our study.

Different studies have been generated with possible analgesic effects of popular medicinal plants [4]. In this sense, the present work shows for the first time that lyophilized pomegranate juice from a specific variety of the state of Hidalgo showed antinociceptive effects in the early phase (activation of peripheral nociceptors) and late phase (reflects the ongoing peripheral activity and central sensitization related to an inflammatory pain). Our findings agree with similar results obtained by other groups of researchers; it has been reported that some pomegranate products that include juice and seed extracts [17], extracts of flowers [18], leaves, fruit peel [19], seeds [17], or whole fruit [7], have shown antinociceptive and anti-inflammatory effects [7]. These findings were performed in different phases and various experimental models $[7,20]$. These effects may be attributed to their diverse bioactive phytochemicals as ellagitannins, ellagic acid, or anthocyanins [7], which may be attributed to its antioxidant capacity. The effect of pomegranate antioxidant compounds on pain modulation is related to the elimination of free radicals [21], decreases macrophage oxidative stress [22], and enhances the biological actions of naturally produced nitric oxide (NO) [23-25]. There is also evidence that shows that the NO acts as a modulator in the spinal cord and dorsal root ganglia through the nociceptive pathway [26].

However, the precise mechanism by which pomegranate products and their bioactive phytochemicals enhances the analgesia has not been completely clarified yet. Therefore, more studies should be carried out to know the possible mechanisms related to the pomegranate antinociceptive effect.

\section{CONCLUSION}

This is the first study to demonstrate that lyophilized juice of pomegranate obtained from the state of Hidalgo, Mexico, reduces painful behavior in nociceptive and inflammatory pain. Nevertheless, future research is needed to discern the possible action mechanisms responsible for this effect.

\section{ACKNOWLEDGMENT}

This article was presented in the 5th International Conference on Pharmacy and Pharmaceutical Science 2020 (ICPPS). We thank the 5th ICPPS committee, who had supported the peer review and manuscript preparation before submitting to the journal

\section{FUNDING}

This study is part of the $\mathrm{PhD}$ of José Antonio Guerrero-Solano, a CONACyT fellow (fellowship number 554424).

\section{AUTHOR'S CONTRIBUTIONS}

All the authors have contributed equally.

\section{CONFLICTS OF INTEREST}

All authors have none conflicts of interest.

\section{REFERENCES}

1. Ong CK, Lirk P, Tan CH, Seymour RA. An evidence-based update on non-steroidal anti-inflammatory drugs. Clin Med Res 2007;5:19-34.

2. Goldberg D, McGee S. Pain as a global public health priority. BMC Public Health 2011;11:1-5.
3. da Rocha JL, de Tripodi Calamby RF, da Silva DF, Brandao HN, Villarreal CF, de Lima FO. Evaluation of biological activity of Polygala boliviensis in experimental models. Iran J Pharm Res 2019;18:793-802.

4. Newman D, Cragg G. Natural products as sources of new drugs over the last 25 years. J Nat Prod 2007;70:461-77.

5. Mena P, Girones-Vilaplana A, Marti N, García-Viguera C. Pomegranate varietal wines: Phytochemical composition and quality parameters. Food Chem 2012;133:108-15.

6. Miguel MG, Neves MA, Maria DA. Pomegranate (Punica granatum L.): A medicinal plant with myriad biological properties a short review. J Med Plant Res 2010;4:2836-47.

7. González-Trujano ME, Pellicer F, Mena P, Moreno DA, GarcíaViguera C. Antinociceptive and anti-inflammatory activities of a pomegranate (Punica granatum L.) extract rich in ellagitannins. Int J Food Sci Nutr 2015;66:395-9.

8. Labib RM, El-Ahmady SH. Antinociceptive, anti-gastric ulcerogenic and anti-inflammatory activities of standardized Egyptian pomegranate peel extract. J Appl Pharm Sci 2015;5:48-51.

9. Mansouri MT, Naghizadeh B, Ghorbanzadeh B. Ellagic acid enhances the antinociceptive action of venlafaxine in mouse acetic acid-induced pain: An isobolographic analysis. Pharmacol Rep 2015;67:473-7.

10. Ferreira LM, Sari MH, Cervi VF, Gehrcke M, Barbieri AV, Zborowski VA, et al. pomegranate seed oil nanoemulsions improve the photostability and in vivo antinociceptive effect of a non-steroidal antiinflammatory drug. Colloids Surf B Biointerfaces 2016;144:214-21.

11. Zimmermann M. Ethical guidelines for investigation of experimental pain in conscious animals. Pain 1983;16:109-10.

12. Nair VG, Praiapati PK, Nishteswar K, Unnikrishnan V, Nariva MB. Analgesic and anti-inflammatory activities of Bulbophyllum neilgherrense Wight. Pseudobulb: A folklore plant. Ayu 2018;39:76-80.

13. Gibaldi, M. Estimation of area under the curve. In: Gibaldi M, editor. Biopharmaceutics and Clinical Pharmacokinetics. $4^{\text {th }}$ ed. Philadelphia, PA: Lea and Febiger; 1991. p. 377-8.

14. Meunier CJ, Burton J, Cumps J, Verbeeck RK. Evaluation of the formalin test to assess the analgesic activity of diflunisal in the rat. Eur J Pharm Sci 1998;6:311-6.

15. Rosland JH, Tjolsen A, Maehle B, Hole K. The formalin test in mice: Effect of formalin concentration. Pain 1990;42:235-42.

16. Bozimowski G. A review of non-steroidal anti-inflammatory drugs. AANA J 2015;83:425-33.

17. Malek Z, Dara SM, Jahromy MH. Antinociceptive effects of pomegranate (Punica granatum L.) juice and seed extracts on acute corneal pain in mice. World J Neurosci 2014; 4:99-105.

18. Sarker M, Das SC, Kumar-Saha S, Al Mahmud S, Bachar C. Analgesic and anti-inflammatory activities of flower extracts of Punica granatum Linn. (Punicaceae). J Appl Pharm Sci 2012;2:133-6.

19. Salwe KJ, Sachdev D. Evaluation of antinociceptive and antiinflammatory effect of the hydroalcoholic extracts of leaves and fruit peel of $P$. granatum in experimental animals. Asian J Pharm Clin Res 2014;7:137-41.

20. Larrosa M, González-Sarrías A, Yaañez-Gascón MJ, Selma MV, Azorín-Ortuño $\mathrm{M}$, Toti $\mathrm{S}$, et al. Anti-inflammatory properties of a pomegranate extract and its metabolite urolithin a in a colitis rat model and the effect of colon inflammation on phenolic metabolism. J Nutr Biochem 2010;21:717-25.

21. Noda Y, Kaneyuki T, Mori A, Packer L. Antioxidant activities of pomegranate fruit extract and its anthocyanidins: Delphinidin, cyanidin, and pelargonidin. J Agric Food Chem 2002;50:166-71.

22. Jurenka JS. Therapeutic applications of pomegranate (Punica granatum L.): A review. Altern Med Rev 2008;13:128-44.

23. Ignarro LJ, Byrns RE, Sumi D, Nigris FD, Napoli C. Po megranate juice protects nitric oxide against oxidative destruction and enhances the biological actions of nitric oxide. Nitric Oxide 2006;15:93-102.

24. Vasantharaja D, Ramalingam V. Neurotoxic effect of titanium dioxide nanoparticles: biochemical and pathological approach in male wistar rats. Int J App Pharm 2018;19:74-81.

25. Hasan H, Oktawaty S, Kadang PM. Efficacy of pomegranate peel extract, mangosteen peel extract, and combination of both extract on incision wound healing in mice. Int J App Pharm 2019;11:5-7.

26. Toda N, Kishioka S, Hatano Y, Toda H. Modulation of opioid actions by nitric oxide signaling (review). Anesthesiology 2009;1 Suppl 10:166-81. 